attendances. Cases in which the patient does not survive the operation thirty-six hours, or in which he does not receive several subsequent attendances, may be included in the contract of the medical officer with the guardians.

Art. 15. If any medical officer has a partner or assistant who is a duly qualified medical man, he may name such partner or assistant under this article.

The medical officer will be considered by the commissioners as responsible for the skill and diligence of the person named by him as a substitute.

Arts. 16-19 are intended to facilitate the obtaining of attendance and medicines by the permanent paupers; a class whose destitution is acknowledged, and which necessarily includes the most helpless portion of the community.

Art. 20 places the medical officer on the same footing with the other officers, as to the period of his office, unless such period be specially limited at the time of his appointment. It does not seem desirable to exclude the guardians from the opportunity of improving the arrangements respecting medical relief as the circumstances of the several districts may permit, and therefore it is not advisable to deprive them of the power of limiting the period of the medical officer's services.

The commissioners intend, in a short time, to issue a general order prescribing the adoption, by the medical officers, of the nomenclature of diseases now in use under the authority of the registrar-general, which will ensure greater uniformity and precision of language in the returms made by the medical officers, and will furnish a convenient interpretation of many of the more obscure scientific names of diseases.

(Signed by order of the board)

Edwin Chadwick, Secretary.

\section{THOUGHTS ON THE POOR-LAW,}

WITH REFERENCE TO THE

\section{MEDICAL CARE OF THE POOR.}

\section{By J. D. Jefferr, Surgeon, Sidmouth.}

\section{The Real Wants of the Poor.}

The real wants of the poor, as regards their superiors, may be chiefly comprised under the heads of protection, example, instruction for their children in early years, the power of obtaining employment, and relief under circumstances of destitution or disease.

The poor man requires "protection" at the hands of his superiors in almost every sense in which the word can be understood. As the vine clings with its tendrils to the tree or wall for the support of its weak and slender stem, so does the grape-producing portion of human society rely on the kind assistance and judicious legislative enactments of the better classes for help and encouragement in that striving and precarious course which it is destined to pursue through life.

In the brute creation the powers of oppression and destruction seem to reign in full force; the stronger preys upon the weaker, and each, in turn, succumbs to its natural foe; but here, with equally unerring strength, the laws of instinct come into action; the brute satisfies his hunger, the victim or victims are sacrificed, and with this the persecution ends, until the stimulus of nature's demand again excites it, and thus a limit is set beyond which neither animal wants or passions extend.

But in human society the case is different; the instinctive feelings for self-support and self-protection do indeed exist as constituting one of the first principles of our nature, but as distinguished from the brute our reason comes into play as a powergiven to us to range beyond the confined and narrow boundary of merely animal sense, and the possession of which makes us im- mediately responsible beings. Inasmuch, then, as we are permitted to possess and enjoy an extent of intelligence which gives great freedom to our thoughts, desires, and actions, so are we bound by every law of duty and religion to exercise that intelligence as private individuals with reference to the general good of society; and in a public capacity, where it is coupled with power, with humanity, charity, and a due and faithful consideration for the real wants and feelings of our inferiors.

I waive the consideration of other duties, both moral and religious, which it is incumbent on the rich and powerful to perform towards the poor; I confine myself to that portion which is included under the head of relief under circumstances of sickness or disease, and will endeavour to show-

2. That it is a matter of serious importance to the community at large that the poor should not only have the best but the speediest medical assistance, viewed as a matter of pecuniary as well as physical benefit.

The "pecuniary" benefit which those who contribute towards parochial expenditure would derive from a watchful and anxious regard for the health of the poor, appears to me to be scarcely, if at all, taken into that consideration by the framers of the "Poorlaw" as it really and truly merits. It seems to have been deemed sufficient that a clause should be inserted for the provision of a medical attendant in a parish or district. So far is the provision good and just; but if, in applying it, the poor-law commissioners have been instructed or allowed to advise and enforce the meanest parsimony in their arrangements for medical care-if they, taking advantage of the peculiar position of the medical practitioner in his neighbourhood, have ground him down to terms in which his stimulus to exertion, if not his responsibi lity, is buried-if, again, they have, for the sake of saving, pampered the greedy appetites of those who could be so unconscientious as to undertake it, allotted to them an extent of country, and care of numbers, such as it wonld be utterly impossible for them properly to attend-or if they have entrusted the lives of their fellow-creatures to the unskilled hand and head of the unqualified adventurer-then, indeed, may the provision become an injury rather than a blessing, an expense rather than a good and saving. That such has been the case, and probably may be found to be so now, is but too true; and for the consequences, I appeal to the prolonged sufferings of the sick, to the distresses of the for-ever-pauperised family, to the cry of the orphan, and last, though not least, perhaps, in the estimation of some, to the ultimate increased demands upon the parochial funds.

It is a fact not to be contradicted that sickness is one of the leading causes of poverty ; it behoves those, therefore, who contribute towards and provide for the relief of the poor, to endeavour to guard them, as much as possible, from all those causes which tend to induce disease, to which they are so peculiarly exposed, and to ensure also for them such efficient and timely medical care in actual sickness, as that they may have every fair chance of a speedy recovery, and of being enabled to return to their employment, and work for the support of themselves and families. Every case of sickness among the poor must be attended with more or less expense to the parish, even when it occurs among the inferior members of a family; but if the father-the working man-is laid up, a number besides himself are thrown upon the funds of charity. Hence I lay a stress upon the easiness of accessibility to medical advice, as constituting an ingredient of great import in the regulations for medical relief.

The urgent demands which the family of the labourer make upon him for the proceeds of his labour, tend to cause injurious delay in illness; and where the access to medical assistance is not free, or 
where it is encumbered with any formal process, however slight, such as even applying to an overseer or other proper authority for an order, the delay is still greater, and he does not complain or give up until his strength fails him, and disease has made some progress. It would be better for the surgeon and the parish, as well as for himself, that the pauper should resort early to medical advice; timely assistance, we all know, in incipient illness, will often ward off dangerous, and perhaps fatal, disease. The surgeon would, probably, have more frequent applications, but he would not have so many serious demands upon his time and anxiety, and in opposition to the tenacious regulations at first established regarding the case system, I think that which would seem at first sight to be an anomaly, would be proved to be true-viz., that the more cases in which the medical man prescribes for, the greater number of shillings, and even pounds, would be saved to the parish.

The (I believe almost general) abandonment of the case system, and the allotment of salaries to medical officers, will do much towards effecting the above object; and it has often suggested itself to my mind whether or not more freedom conld be given to the pauper by his being furnished with a printed card on his receiving relief, which would enable him to obtain medical assistance easily and speedily; the card to be signed weekly by the relieving officer, or subjected to some other restrictive regulation. Another very important consideration, which refers to the distance and number of parishes which a surgeon is deputed to attend, is the great length of time which must necessarily elapse before the patient can receive the medicines prescribed for him. It seems to me that if the plan of establishing district dispensaries could be effected, much of this evil would be obviated; then the medical man, in going his rounds, would be constantly dismissing his prescriptions at every visit he makes, and his medicines would be taken long, probably, before he arrives home, until some time after which, according to the present system, they cannot be dispensed. I question whether, by making some small deduction from the medical officer's salary, this plan would not be found, in the end, equally economical, and certainly more comfortable and beneficial both to the practitioner and patient.

The physical benefit which the better classes of society must derive from the sanatory state of the poorer, is a subject which, one would have thought, in this present enlightened eye, would have met with that due and serious consideration to which it is entitled. The rich, it is true, are gencrally very careful to avoid those houses or districts where contagious disease is known to prevail; and, with the observance of this caution, they are satisfied to rest quiet, and too often revel in fancied security. But, alas! the plant has grown and flourished, and the winds of Heaven waft its fatal seeds to softer beds and no less congenial soil, where again it buds and thrives, and death and sorrow nurse its growth. In a word, it is in the narrow strects of the town and ill-ventilated house of the poor man, that epidemic disease generally first takes its root; and but too often, having fed on the meagre, though favourable diet of the hovel and the alley, does it breathe its deadly breath into the rich man's house and noble's mansion.

Since, then, it is seen that the health of the poor so powerfully affects all other grades of society, is it not a matter of serious importance, that in every provision for their necessities, that which relates to their wants in sickness, and to the guarding them as much as possible from its invasion, should hold a prominent place in the consideration and arrangements of the legislative portion of the public ? Besides the purely medical department of sanatory law, how much good might be done nationally, as well as individually, by a careful inspection of the houses of the poor, if only once in the hottest and coldest seasons of the year, by a removal of filth and infecting matter which will accumulate among them, and by a timely administration of necessary comforts, is incalculable !

I am fully aware that no human precaution can ever free us, altogether, from the presence of disease and suffering, for such is the common lot of our nature. But I do contend that, if there be any virtue in medicine, or value in medical science, or if we are allowed by any means to be able to alleviate suffering, or ward off disease, or humanely speaking, to save or prolong life, "I contend," I say, " that it becomes our bounden duty to make use of those means, and apply them according to the best of our ability and judgment."

If there be any truth, then, in what I have above stated, I can only infer, that morally speaking; it must be a wicked act in any person, or body of persons, to withhold or improperly provide that medical advice and assistance to the poor which it is in their power and their duty to give, and which the poor ought to receive; that in a pecuniary point of view it is a foolish and expensive act, as I have endeavoured to show, because by so doing, parochial expenditure must be ultimately increased; and lastly, that physically speaking, it is injurious and destructive, and will be sure to recoil with double force on the heads of those who fancy themselves free from its operation.

\section{REGULATION OF LUNATIC ASYLUMS.}

\section{TO THE EDITORS OF THE PROVINCIAL MEDICAL AND} SURFICAL JOURNAL.

Gentlemen, - Having always taken a lively interest in anything calculated to improve the condition of those unfortunate individuals who are suffering from mania, and having also paid some little attention to that peculiar branch of our profession, the treatment of insanity, I looked forward with some degree of pleasure for Lord G. Somerset's new plan for regulating lunatic asylums. A few evenings since I read his lordship's speech on introducing his bill to the House of Commons, reported in the "Morning Herald" of the 18th instant, in which I find the following paragraph:- "He was not inclined to introduce complexity or difficulties into the mode of making out and signing certificates by the medical men consulted in the case of persons alleged to be insane. For these reasons he intended that the certificates themselves should in substance remain as they were, because he considered they were sufficiently stringent upon respectable members of the medical profession; but it was his intention to remove and take away from the apothecary and surgeon the power to sign certificates, which should authorise the consignment of parties supposed to be insane to receptacles for lunatics. The right to give such certificates he intended to confer only upon members of the College of Physicians. He thought that the public was not at all aware of the vast number of persons confined on the plea of insanity in private houses without any regular medical attendance, or the care and attention paid to their cases by persons experienced in attending on insane patients, which were often so conducive to recovery."

Now, if this is not an insult to the surgeon and the apothecary, it is an uncalled-for insinuation. I am not going to take up the cudgels on behalf of the whole of the general practitioners, but I must beg to assure his lordship that whenever a surgeon or an apothecary is called on to sign a certificate to consign to a lunatic asylum an unfortunate maniac, he believes he is doing that which was best calculated to restore the patient to health and reason; and in doing this he is acting quite as conscientiously as one who may by chance have M.D. attached to his name. 